\title{
Leishmaniose tegumentar no Brasil: revisão histórica da origem, expansão e etiologia ${ }^{*}$ Tegumentary leishmaniasis in Brazil: a bistorical review related to the origin, expansion and etiology"
}

Everton Carlos Siviero do Vale ${ }^{1}$

\section{INTRODUÇÃO}

Em 1925, no primeiro e segundo fascículos do volume um dos Annaes Brasileiros de Dermatologia e Syphilographia, Eduardo Rabello publica na seção de "Memórias Originais" o trabalho intitulado "Contribuições ao estudo da leishmaniose tegumentar no Brasil" (Figura 1), que tratava do histórico e da sinonímia da doença. ${ }^{1}$

Naquela revisão, conclui o autor que a leishmaniose tegumentar (LT) já existia no país desde muitos anos e distingue três períodos na história da doença. O primeiro, de origem incerta e baseada em referências vagas, vai até 1895 , ano da observação clínica do 'botão da Bahia' e sua filiação ao 'botão do Oriente'. O segundo estende-se até 1909, quando é identificado e descrito o agente etiológico da 'úlcera de Bauru'. O terceiro se inicia em 1910 com o achado do parasita em lesões mucosas, então incorporadas ao quadro clínico da doença, indo até a época da publicação do artigo.

Estudos arqueológicos desenvolvidos em buacos peruanos - vasos de cerâmica com reprodução de figuras humanas sadias e mutiladas por diferentes moléstias - puderam assegurar a ocorrência da uta e espundia - denominações locais para as formas cutânea e mucosa da LT, respectivamente entre os incas durante a era pré-colombiana, embora a princípio tenham sido confundidas com a sífilis. Ao contrário, estudos das cerâmicas antropomórficas produzidas por nossos ancestrais indígenas, por seu caráter rudimentar, não permitiram a mesma constatação. A única indicação segura e talvez mais antiga da existência da doença no Brasil
Tancredo Furtado ${ }^{2}$

verifica-se em citação na tese de Tello, "Antiguedad de la syphilis en el Perú", de 1908, relativa à obra escrita, Pastoral Religioso-Político Geographico, editada em 1827, que descreve a viagem de um missionário pela região amazônica. Este observara a existência de indivíduos com úlceras nos braços e pernas, relacionadas a picadas de insetos, tendo como conseqüência lesões destrutivas de boca e nariz. Sem ter sido mencionada anteriormente no Brasil, Rabello achava mais razoável supor que, endêmica na Amazônia, porém proveniente do Peru e da Bolívia, a doença pudesse ter-se disseminado nos estados do Norte do país por indivíduos que para lá se dirigiram em busca de trabalho nos seringais e que retornaram infectados a suas origens. Quanto às regióes Centro e Sul do Brasil, achava mais verossímil a importação da Bolívia ou da Amazônia, via Mato Grosso, e provavelmente também do Paraguai, via Mato Grosso ou Paraná, considerando sua existência de forma endêmica naqueles países, muito antes do descobrimento. É provável que esse longo período de indenidade tenha sido determinado pelo isolamento, em conseqüência da precariedade de tráfego na época. Considerava ainda serem fortes evidências da ocorrência da doença também na região Centro-Sul do Brasil, no final do século XIX, os seguintes fatos: a) modelos encontrados no Museu da Faculdade de Medicina do Rio de Janeiro, datados de 1882 a 1884, que representam casos indubitáveis de LT; b) casos diagnosticados em imigrantes italianos de São Paulo que retornaram a seu país, descritos por

Recebido em 20.07.2005

Aprovado pelo Conselho Consultivo e aceito para publicação em 27.07.2005

* Trabalho realizado no Serviço de Dermatologia, Hospital das Clínicas, Universidade Federal de Minas Gerais (UFMG), Belo Horizonte (MG), Brasil.

\footnotetext{
Professor Assistente e Mestre em Dermatologia, Departamento de Clínica Médica, Faculdade de Medicina da Universidade Federal de Minas Gerais (UFMG) - Belo Horizonte (MG), Brasil; Pós-graduado em Imunodermatologia na Universidade de Munique - Alemanha.

Professor Emérito da Faculdade de Medicina da Universidade Federal de Minas Gerais (UFMG) - Belo Horizonte (MG), Brasil.
}

(C)2005 by Anais Brasileiros de Dermatologia 


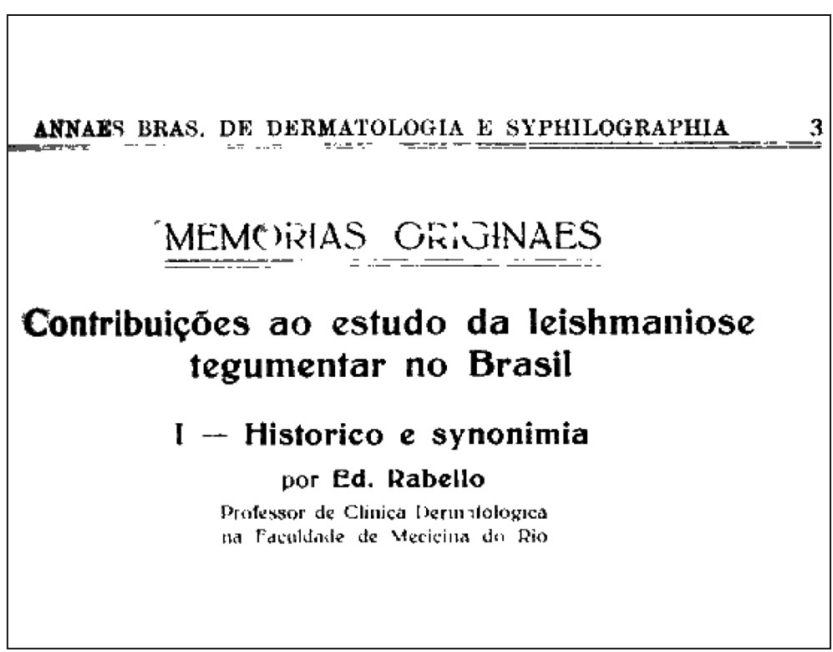

Figura 1: Reprodução do título do artigo de Rabello, publicado nos Anais em 1925

Breda (1884), na Itália, como 'buba brasiliana' (Figura 2); c) reproduções em aquarela de casos de afecções ulcerosas do nariz apresentados à Sociedade Brasileira de Dermatologia em 1912 (Figura 3), observados por Carneiro da Cunha em 1906, em pacientes provenientes de Uberaba, Minas Gerais, que as apresentavam há 27 anos, portanto desde 1879 .

O segundo período da história da LT no Brasil inicia-se com Juliano Moreira, que, estudando o chamado 'botão da Bahia', em 1895 relacionao pela primeira vez ao 'botão endêmico dos países quentes', quando então é sugerida a possível impor-

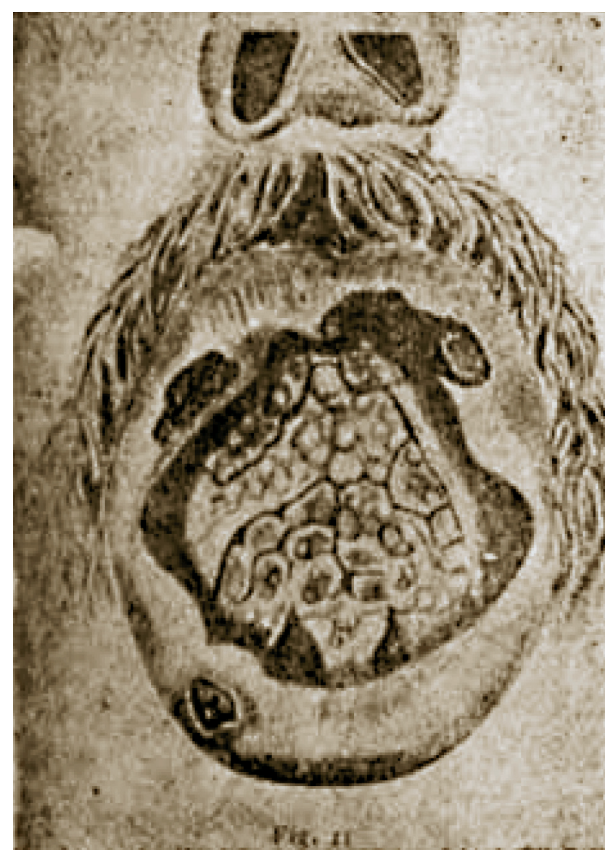

Figura 2:

Reprodução de gravura de Breda (1884), ilustrando caso de LTA, por ele denominada buba brasiliana

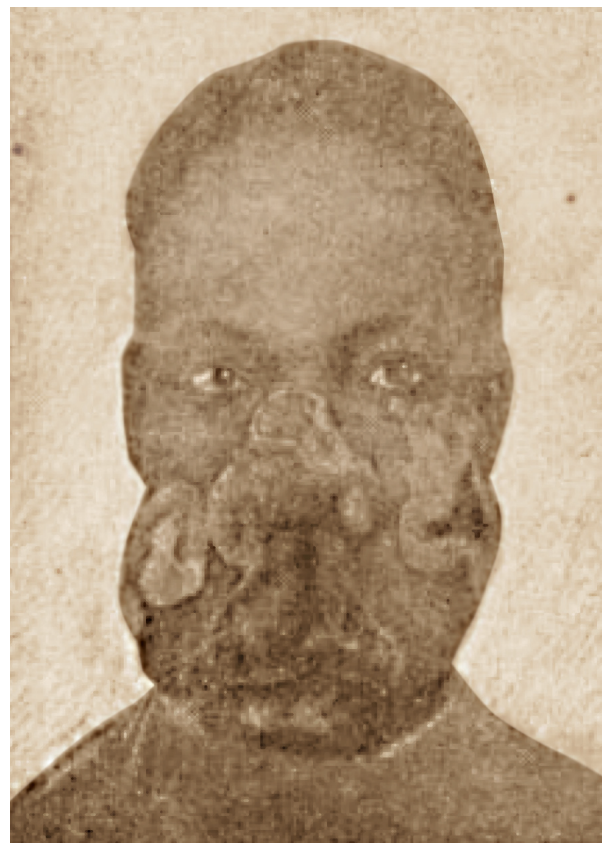

FIGURA 3: Reprodução de aquarela, apresentada por Carneiro da Cunha em 1912 à Sociedade Brasileira de Dermatologia, ilustrando caso de LTA por ele observado em 1906

tação da doença, por meio de incursões sírias ao Novo Mundo em tempos remotos, opinião na época não compartilhada por observadores de outras regiões do país. Baseando-se em tese de doutoramento de Adeodato apresentada à Faculdade de Medicina da Bahia em 1895, Rabello atribui essa correlação a Moreira e não a Cerqueira, que na verdade desde 1885 teria visto doentes com 'botão da Bahia', sem, entretanto, estabelecer qualquer associação entre ambas.

Em 1903 Wright identifica o Helcosoma tropicum como agente do 'botão do Oriente', mais tarde denominado Leishmania furunculosa, o que permitiu filiarem-se à leishmaniose várias dermatoses com denominações diversas, geralmente designando as regiões geográficas atingidas. A grande epidemia de casos de úlceras acompanhadas de lesões mucosas no início do século XX no Estado de São Paulo, com a construção da Estrada de Ferro Noroeste, descritos como 'úlcera de Bauru', prenuncia o fim do segundo período, que culmina com a identificação do agente em 1909, quase simultaneamente por Lindenberg e por Carini \& Paranhos.

O terceiro período é considerado o mais profícuo segundo Rabello, porque a identificação do agente permitiu a constatação da endemia em diversos pontos do país, como o Vale do Rio Doce em Minas Gerais, região amazônica e sul da Bahia, entre outros. Seu início é marcado pelo achado do agente em lesões mucosas por Splendore, em 1910. Fato culminante desse período foi a descoberta do tratamento com o tártaro emético por Gaspar Vianna em 1911, comunicada em 1912, 
durante o Congresso de Dermatologia realizado em Belo Horizonte.

Ao final da primeira parte de seu trabalho, Rabello conclui ter ficado demonstrada há muito tempo a presença da leishmaniose cutâneo-mucosa no país, designada por expressões regionais, como 'botão da Bahia' e 'buba brasiliana', ou denominações vagas, como 'ferida brava'. Descoberta a leishmânia como agente etiológico do 'botão do Oriente' e também verificada nas condições acima referidas, estas puderam ser incluídas sob o mesmo critério nosográfico. Em 1909, Lindenberg sugere a designação 'leishmaniose ulcerosa'. Reconhecidas as manifestações mucosas, infiltrativas e vegetantes além de ulcerosas, aquela denominação não poderia mais subsistir. Assim, propõe Rabello a expressão 'leishmaniose tegumentar' que, abrangendo as lesões cutâneas e mucosas de diversa morfologia, permite sua distinção da forma visceral de leishmaniose. $\mathrm{Na}$ época o autor encontrava duplo inconveniente na denominação de 'leishmaniose americana das florestas', proposta em 1913 por Brumpt \& Pedroso, tanto por dar delimitação geográfica à doença como por fazer da ocorrência em florestas elemento preponderante. Chamava a atenção para o fato de a doença existir e se propagar fora de florestas virgens, referindo-se a diversos casos observados na zona urbana do Rio de Janeiro já naquela época. Em seguida reconhece serem muitos dos casos de gangosa - rinofaringite mutilante - manifestações de LT. Também comenta a impossibilidade de distinção, na época, entre as leishmânias encontradas na leishmaniose tegumentar no Brasil e aquelas presentes no 'botão do Oriente', considerando por isso imprópria a denominação ' $L$. brasiliensis' dada por Gaspar Vianna em 1911, o que leva o autor a questionar a doença no Brasil como entidade autônoma. Discute em seguida outros argumentos a favor de entidade nosológica única. Entre esses refere: a) a atribuição ao caráter fagedênico de determinadas moléstias nos trópicos, provavelmente pela ingerência de germes secundários; b) a predominância de formas cutâneas benignas no Brasil, algumas vezes auto-resolutivas; c) a observação ocasional de formas cutâneas agressivas e mutilantes de 'botão do Oriente', assim como a demonstração de manifestações de leishmaniose mucosa grave no Sudão, Egito e Índia; d) a semelhança das alterações histopatológicas da doença em ambas regiões; e) a possibilidade, nos trópicos, da associação de outras doenças que poderiam mascarar o quadro original da LT. Conclui Rabello que "não poderá, por conseqüência, subsistir a designação de 'americana', para uma doença que, sem ter etiologia diversa e quadro ana- tomoclínico autônomo, já começa a ser vista fora da América e cuja zona de propagação será de futuro, evidentemente ampliada".

\section{CARACTERIZAÇÃO DO AGENTE DA LEISHMA- NIOSE TEGUMENTAR AMERICANA NO BRASIL}

No passado admitia-se a Leishmania braziliensis como único agente da leishmaniose tegumentar americana (LTA) existente no país. Até o início da década de 1960 as classificações dos parasitas baseavam-se exclusivamente no comportamento clínicoevolutivo, configurando formas clínicas da doença nas diversas regiões geográficas, posto que a morfologia dos parasitas à microscopia óptica não permitia sua distinção. ${ }^{2}$ Em 1961 Pessoa já propunha a subdivisão da $L$. braziliensis nas variedades braziliensis, guyanensis, peruviana, mexicana e pifanoi, que estariam relacionadas a formas clínicas diversas da doença em diferentes regiões. ${ }^{3}$

A partir daí, a classificação das leishmânias ganhou novo impulso, com a distinção dos complexos mexicana e braziliensis, baseada em critérios mais consistentes, como as características do comportamento do parasita em meios de cultura, animais de experimentação e vetores. ${ }^{4}$

Desde então os avanços representados pela microscopia eletrônica, biologia molecular, bioquímica e imunologia abriram novas perspectivas na taxonomia das leishmânias. ${ }^{5}$ Os novos métodos que passaram a ser empregados na caracterização das leishmânias incluem principalmente o estudo do desenvolvimento dos promastigotas no intestino do vetor flebotomíneo, ${ }^{6}$ o estudo morfométrico das formas amastigotas e promastigotas à microscopia eletrônica, $^{7-9}$ a mobilidade eletroforética de isoenzimas, ${ }^{10}$ a determinação da densidade flutuante do DNA do núcleo e do cinetoplasto, ${ }^{11,12}$ a análise de produtos de degradação do DNA por enzimas de restrição, ${ }^{13}$ a radioespirometria, ${ }^{14}$ a caracterização de antígenos específicos de membrana externa pelos anticorpos monoclonais, ${ }^{15}$ as técnicas de hibridização do DNA/RNA ${ }^{16,17}$ e a análise do DNA do cinetoplasto por meio da técnica de amplificação pela reação da cadeia da polimerase. ${ }^{12,18}$

As classificações mais utilizadas na atualidade seguem o modelo taxonômico proposto por Lainson \& Shaw (1987), ${ }^{19}$ que dividem as leishmânias nos subgêneros Viannia e Leishmania. No Brasil são reconhecidas pelo menos sete espécies de Leishmania responsáveis por doença humana, sendo a forma tegumentar causada principalmente pela $L$. (V) braziliensis, L. (V.) guyanensis e L. (L.) amazonensis e, mais raramente, pela $L$. (V.) lainsoni, L. (V.) naiffi e $L$. (V.) shawi, enquanto a $L$. (L.) chagasi é a responsável pela doença visceral. ${ }^{12}$ Cada espécie 
apresenta particularidades concernentes às manifestações clínicas, a vetores, reservatórios e padrões epidemiológicos, à distribuição geográfica e até mesmo à resposta terapêutica.

\section{DISTRIBUIÇÃO GEOGRÁFICA DA LEISHMANIOSE TEGUMENTAR AMERICANA NO BRASIL}

Até a década de 1950 a LTA disseminou-se praticamente por todo o território nacional, coincidindo com o desflorestamento provocado pela construção de estradas e instalação de aglomerados populacionais, com maior incidência nos estados de São Paulo, Paraná, Minas Gerais, Ceará e Pernambuco. A partir daí até a década de 1960, a doença parece ter entrado em declínio, com o desmatamento já completado nas regiões mais urbanizadas do país, além da relativa estabilidade das populações rurais. ${ }^{2}$

Desde então, em áreas de colonização antiga, novos surtos vêm sendo assinalados em diversos estados. ${ }^{20}$ No Rio de Janeiro foram particularmente relatados na Ilha Grande, em Jacarepaguá, Campo Grande e Parati. ${ }^{21}$ Em Minas Gerais, além da permanência dos antigos focos endêmicos na região de mata atlântica nos vales do Rio Doce e Mucuri, ${ }^{22}$ foram registrados numerosos casos fora dessas áreas, alguns na região metropolitana de Belo Horizonte. ${ }^{23}$ Novos focos foram descritos em São Paulo, no Vale do Mogi-Guaçu e na zona litorânea do Vale da Ribeira, ${ }^{24}$ e grande foco foi observado na periferia da capital do Espírito Santo, nos municípios de Viana e Cariacica. ${ }^{25}$ Também no Nordeste a LTA persiste como endemia em áreas de civilização antiga, especialmente nas zonas serranas dos estados do Ceará, Paraíba e Bahia. ${ }^{26}$

Nos últimos 20 anos tem sido observado franco crescimento da endemia, tanto em magnitude quanto em expansão geográfica, com surtos epidêmicos na regiões Sul, Sudeste, Centro-Oeste, Nordeste e, mais recentemente, na Região Norte. ${ }^{27}$ Nas áreas de colonização recente, a expansão está associada à derrubada de matas para construção de estradas, novos núcleos populacionais e ampliação de atividades agrícolas, sendo mais comum na Amazônia $^{28}$ e Centro-Oeste, onde atinge principalmente a população migrante, freqüentemente poupando os indígenas. ${ }^{2}$

Entre 1985 e 1999 foram registrados 388.155 casos da doença no país, sendo que no último ano foram verificados os maiores coeficientes de detecção nas regiões Norte $(92 / 100.000)$ e Centro-Oeste (50/100.000), especialmente nos estados de Mato Grosso, Amapá, Rondônia, Acre, Pará, Amazonas, Tocantins e Roraima, além de Maranhão, na Região Nordeste. ${ }^{27}$

\section{TEORIAS SOBRE ORIGEM E EXPANSÃO DA LEISHMANIOSE TEGUMENTAR AMERICANA NO BRASIL}

Os progressos na biologia e epidemiologia da LTA permitiram a evolução do conhecimento sobre a origem e a expansão da doença. Em 2003, Altamirano-Enciso et al. fazem interessante revisão sobre esse tema, a partir de fontes históricas pré- e pós-colombianas. ${ }^{29}$

Com a descrição do 'botão da Bahia' e sua filiação ao 'botão do Oriente', surgia a primeira teoria da origem 'mediterrânea' da LTA, que teria sido importada durante as viagens de fenícios ou sírios ao Nordeste brasileiro ainda na Antigüidade, ${ }^{30,31}$ embora essas viagens nunca tenham sido comprovadas.

A segunda teoria seria a 'andina', formulada por Rabello em 1925, ${ }^{1}$ a partir dos descobrimentos dos buacos peruanos. Embora não aceita por todos os estudiosos do assunto, ${ }^{32}$ a proposta de Rabello sobre a origem da LTA em territórios frios, nas regiões da Bolívia e do Peru, é a que predomina na literatura biomédica. $^{29}$

A terceira teoria, a 'amazônica', foi proposta por Marzochi \& Marzochi em $1994,{ }^{33}$ com base em estudos epidemiológicos e de distribuição geográfica da Leishmania (Viannia) braziliensis em diferentes ecossistemas, envolvendo vetores e reservatórios diversos. Sugerem que a doença humana tenha surgido na região amazônica ocidental, principalmente ao sul do rio Marañon-SolimõesAmazonas, onde predomina a $L$. (V.) braziliensis. Em acordo com a hipótese de disseminação da LTA sugerida por Rabello, admitem ainda que o processo de dispersão para outras áreas do Brasil é recente e que tenha ocorrido sobretudo durante o ciclo econômico da borracha, entre 1880 e 1912, que atraiu milhares de nordestinos - essa população, após o declínio desse ciclo, retornou às origens ou, atraída pela expansão do cultivo do café, migrou para a Região Sudeste, particularmente Minas Gerais e São Paulo. Essa migração deu-se por volta de 1930, quando se iniciou a grande epidemia da LTA. ${ }^{34}$ Outros ciclos posteriores, que também implicaram mobilidades sociais para o sul da Amazônia, como a construção de estradas (196070), a mineração de ouro (1970-80) e a exploração de madeira (1980-90), teriam contribuído para a expansão da LTA, com reaparecimento em vários estados das regiões Centro-Oeste e Sudeste, e recente aparecimento no Sul, coincidindo com o retorno dos trabalhadores. Deve-se ainda destacar a urbanização da doença verificada nas regiões metropolitanas do Rio de Janeiro ${ }^{35}$ e Belo Horizonte. ${ }^{23}$ 
Este último modelo é reforçado pela comparação entre a heterogeneidade genética da leishmânia observada na região amazônica e a homogeneidade daquela encontrada fora dessa região, ${ }^{18,36}$ sugerindo sua introdução tardia. A persistência da $L$. (V.) braziliensis, demonstrada em cicatrizes de LTA em pacientes ligados a atividades rurais, após vários anos da cura clínica, ${ }^{37}$ corrobora a possibilidade de o homem servir de fonte de infecção e, portanto, também transportar o parasita para outras áreas onde existem os transmissores, fazendo surgirem novos focos da doença.

Um argumento usado para refutar a origem amazônica da LTA seria o fato de, no passado, ela não ter sido observada em indígenas - por isso considerados indenes à doença -, o que fez supor que a LTA não existiria nas florestas até finais do século XIX. Além disso, relatórios de Oswaldo Cruz e Carlos Chagas, em 1913, sobre o vale do Amazonas relatavam a ocorrência de lesões mucosas apenas na população não autóctone. Pesquisas recentes têm demonstrado, pela hipersensibilidade da reação de Montenegro, que é alto o índice de infecção por leishmânia, na forma subclínica, entre nativos da Amazônia brasileira, desde a infância, havendo poucos casos de doença cutânea com elevada tendência à cura espontânea. ${ }^{38}$

A última teoria, entretanto, carecia de confrontação histórica. O estudo etno-histórico de Altamirano-Enciso et al., ${ }^{29}$ com base nas fontes históricas do século XVI (Pizarro, 1571; Santillán, 1563; Loayza, 1586; Ávila, 1598), reforça a teoria de origem amazônica da LTA, particularmente a forma mucosa, entre os limites do Brasil com Bolívia e Peru, que, por intermédio de migrações humanas entre as regiões amazônica e andina em tempos arqueológicos, ascendeu à selva alta e posteriormente às terras quentes interandinas. Sugere ainda que durante o império inca grupos migrantes (mitmaq ou mitimaes) tenham contribuído para disseminar a LTA para diferentes regiões do norte andino e que, mesmo no período da colonização espanhola, a doença continuou espalhando-se para novas regiões das serras interandinas e da costa central, onde flebotomíneos e cães conviviam com comunidades agrícolas, não tendo sido perdido o elo com a Amazônia e incrementando-se a LTA em grupos forasteiros.

Estudos moleculares recentes sugerem que também a $u t a$, forma cutânea da LTA observada nos Andes peruanos e causada pela $L$. (V.) peruviana, tenha surgido na Amazônia há cerca de 500 a mil anos e chegado aos Andes como zoonose, por meio de roedores, alcançando a costa norte. ${ }^{39}$ No entanto, estudos arqueológicos vieram revelar que, no período formativo entre o segundo e o terceiro milênio antes da nossa era, toda essa região estava coberta por exuberante vegetação, constituindo-se numa das principais rotas humanas entre a costa e a selva ${ }^{40}$ Esses estudos biológicos, portanto, também corroboram os dados etnohistóricos e parecem confirmar a origem amazônica da LTA.

Recentemente, Thomas-Soccol et al. formularam a teoria monofilogenética das leishmânias, baseando-se em estudos de DNA mitocondrial de 20 espécies diferentes de leishmânias do mundo, que considera a origem comum dos troncos Viannia e Leishmania, que remontariam aos períodos cretáceo e jurássico, há 120 milhões de anos, quando os continentes ainda estavam unidos na pangéia. ${ }^{41}$ Entretanto persiste polêmica a questão da região de origem das espécies de leishmânias, se neotropical, ${ }^{42,43}$ paleoártica ${ }^{44}$ ou africana. ${ }^{45}$

\section{COMENTÁRIOS FINAIS}

As evidências recentes baseadas em estudos biológicos e etno-históricos permitem afirmar que Rabello acertou quando concluiu que a LTA era endêmica na região amazônica já no início do século XIX, de onde se difundiu para o resto das regiões Norte $\mathrm{e}$ Nordeste do país, por meio de migrações humanas iniciadas com o ciclo da borracha. Errou, entretanto, quando supôs ser a doença originária das terras altas andinas, para posteriormente descer às terras baixas da região amazônica. Estudos atuais têm revelado que a LTA surgiu na Amazônia em tempos arqueológicos e fez a rota inversa, em direção às regiões de florestas altas e posteriormente à região andina, mantendo-se a endemia durante o império inca e o período da colonização espanhola, devido ao fluxo humano em ambos sentidos.

As pesquisas atuais também sugerem que a doença se tenha expandido às demais regiões do país por meio de migrantes que, após o declínio da extração do látex na Amazônia, retornaram a suas origens na Região Nordeste ou se dirigiram para a Região Sudeste, principalmente Minas Gerais e São Paulo, atraídos pelo desenvolvimento gerado pelo cultivo do café. No entanto, essa onda de migração na direção sul teria ocorrido posteriormente à observação de casos na Região Sudeste no final do século XIX e à ocorrência da epidemia de LTA no noroeste paulista durante a primeira década do século XX. Sendo assim, poderia estar certo Rabello de ser a LTA da Região Sudeste proveniente da região amazônica ou mesmo da Bolívia, e nesse caso teria chegado a São Paulo via Mato Grosso. Outra possibilidade seria a importação do Paraguai, via Mato Grosso ou Paraná. Ainda que importada da Bolívia ou Paraguai, a doença seria 
também originária da Amazônia, mas, em todas as possibilidades, decorrente de migrações mais antigas que aquelas ocorridas após a decadência da economia da borracha. Certamente estas últimas migrações poderiam ser responsáveis pela grande epidemia de LTA observada na Região Sudeste a partir da década de 1930, que se estendeu até a década de 1950. Além disso, novas migrações humanas para o sul da Amazônia, geradas pela construção de estradas, exploração mineral e extração da madeira, nas décadas de 1960, 1970 e 1980, teriam colaborado para o surgimento de vários surtos epidêmicos e a franca expansão da endemia nos últimos 20 anos em diversas regiões do país.

Também deve ser comentada a impropriedade da restrita relação da doença às florestas, já destacada por Rabello, opinião decorrente da observação de inúmeros casos urbanos naquela época. Posteriormente constatou-se que a doença pode assumir um dos padrões epidemiológicos distintos. Um clássico, ligado às atividades florestais e ao desmatamento, tendo animais silvestres como reservatórios e que geralmente se verifica na forma de surtos epidêmicos junto às frentes pioneiras de colonização. Outro aparentemente sem relação com a floresta, que geralmente é observado na periferia de centros urbanos, em áreas de colonização antiga, e que possivelmente se deve à adaptação dos parasitas e vetores a alterações ambientais e a animais domésticos como novos reservatórios.

Novamente enganou-se Rabello quando salientou a impropriedade da denominação do agente etiológico como Leishmania braziliensis e afirmou que "...não poderia subsistir a designação 'americana' para uma entidade sem etiologia diversa e quadro anatomoclínico autônomo...", usando como argumentos a dificuldade de sua diferenciação com o parasita do 'botão do Oriente' e a inadequação da delimitação geográfica da doença. Realmente com os recursos disponíveis na época era impossível a distinção entre as diferentes espécies de leishmânia que puderam ser identificadas mais tarde e até correlacionadas com diferentes padrões epidemiológicos, de distribuição geográfica, de manifestações clínicas e até mesmo de resposta terapêutica.

Desde a brilhante revisão histórica de Rabello em 1925, consideráveis avanços foram conseguidos no conhecimento das leishmanioses, sobretudo a biologia das leishmânias e a imunologia da doença. Os métodos diagnósticos foram aprimorados, e os recursos terapêuticos, melhorados. Em que pese o progresso alcançado, é forçoso reconhecer que passados 80 anos a situação dessas doenças pouco se alterou. Elas continuam vivamente presentes na nosologia atual, constituindo-se em importante problema de saúde pública em diversas regiões do mundo, coincidentemente nos países subdesenvolvidos, lado a lado com outras doenças infecciosas e parasitárias, de caráter fundamentalmente social, em conseqüência das marcantes desigualdades que ainda dominam a economia mundial no terceiro milênio.

\section{REFERÊNCIAS}

1. Rabello E. Contribuições ao estudo da leishmaniose tegumentar no Brasil. I. Histórico e sinonímia. Annaes Brasileiros de Dermatologia e Syphilographia. 1925;1(1):3-31.

2. Furtado TA. Leishmaniose tegumentar americana. In: Machado-Pinto J, editor. Doenças infecciosas com manifestações dermatológicas. Rio de Janeiro: Medsi; 1994. p. 319-29;334-6.

3. Pessoa SB. Classificação das leishmanioses e das espécies do gênero Leishmania. Arq Fac Hig S Paulo. 1961;26:41-50.

4. Lainson R, Shaw JJ. Leishmaniasis of the New World: taxonomic problems. Br Med Bull. 1972;28:44-8.

5. Shaw JJ. Taxonomia do gênero Leishmania. Conceito

tradicionalista x conceito moderno. An Bras Dermatol. 1985;60:67-72.

6. Shaw JJ. Taxonomia das leishmânias da Amazônia. An Bras Dermatol. 1982;57:129-32.

7. Shaw JJ, Lainson R. Leishmaniasis in Brazil: XI. Observation on the morphology of Leishmania of the braziliensis and mexicana complexes. J Trop Med Hyg. 1976;79:9-13.

8. Gardener PJ, Shchory L, Chance ML. Species differentiation in the genus Leishmania by morphometric studies with electron microscope. Ann Trop Med Parasitol. 1977;71:147-55.

9. Alexander J. Unusual axonemal doublet arrangements 
in the flagellum of Leishmania amastigotes. Trans R Soc Trop Med Hyg. 1978;72:345-7.

10. Miles MA, Lainson R, Shaw JJ, Povoa M, de Souza AA. Leishmaniasis in Brazil: XV. Biochemical distinction of Leishmania mexicana amazonensis, L. braziliensis braziliensis and L. braziliensis guyanensis - aetiological agents of cutaneous leishmaniasis in the Amazon Basin of Brazil. Trans R Soc Trop Med Hyg. 1981;75:524-9.

11. Worth DF, McMahon Pratt D. Rapid identification of Leishmania species by specific hybridization of kinetoplast DNA in cutaneous leishmaniasis. Proc Natl Acad Sci. 1983;79:6999-7003.

12. Grimaldi Jr. G, Tesh RB. Leishmaniases of the New World: current concepts and implications for future research. Clin Microbiol Rev. 1993; 6:230-50.

13. Jackson PR, Wohlhieter JA, Jackson JE, Sayles P, Diggs CL, Hockmeyer WT. Restriction endonuclease analysis of Leishmania kinetoplast DNA characterizes parasites responsible for visceral and cutaneous disease. Am J Trop Med Hyg. 1984;33:808-19.

14. Decker-Jakson JE, Tang DB. Identification of Leishmania spp by radiorespirometry II: a statistical method of data analysis to evaluate the reproductibility and sensitivity of the technique. In: Biochemical characterization of Leishmania. Proc Workshop Pan Am Health Org. Washington (DC); 1980: p.205-45.

15. McMahon-Pratt D, Bennett E, David JR. Monoclonal antibodies that distinguish subspecies of Leishmania braziliensis. J Immunol. 1982;129:926-7.

16. Barker DC, Butcher J. The use of DNA probes in the identification of leishmanias: discrimination between isolates of the Leishmania mexicana and L. braziliensis complexes. Trans R Soc Trop Med Hyg. 1983;77:285-97.

17. Lopez M, Montoya Y, Arana M, Cruzalegui F, Braga J, Llanos-Cuentas A, et al. The use of nonradioactive DNA probes for the characterization of Leishmania isolates from Peru. Am J Trop Med Hyg. 1988;38:308-14.

18. Lopez $M$, Inga $R$, Cangalaya $M$, Echevarria J, LlanosCuentas A, Orrego C, et al. Diagnosis of Leishmania using the polymerase chain reaction: a simplified procedure for field work. J Am J Trop Med Hyg. 1993;49:348-56.

19. Lainson R, Shaw JJ. Evolution, classification and geo graphical distribution. In: Peters W, Killick-Kendric K, editors. The Leishmaniases in Biology and Medicine. London: Academic Press; 1987. p. 1-120.

20. Furtado T, Vieira JBF. Geografia da leishmaniose tegumentar americana no Brasil. An Bras Dermatol. 1982;57:135-40.

21. Marzochi MCA. Leishmanioses no Brasil. As leishmanioses tegumentares. J Bras Med. 1992;63:82-104.

22. Mayrink W, Williams P, Coelho MV, Dias M, Martins AV, Magalhães PA, et al. Epidemiology of dermal leishmaniasis in the Rio Doce Valley, State of Minas Gerais, Brazil. Ann Trop Med Parasitol. 1979;73:1-14.

23. Passos VMA, Falcão AL, Marzochi MCA, Gontijo CMF, Dias ES, Katz N. Epidemiological aspects of American cutaneous leishmaniasis in a periurban area of Belo Horizonte, MG, Brazil. Mem Inst Oswaldo Cruz. 1993;88:103-10.

24. Bastos JMCMG. Observações à margem de surto epidêmico de leishmaniose tegumentar no Vale da Ribeira (São Paulo). Bol Div Nac Dermatol Sanit. 1978;37:73-86.
25. Sessa PA, Coelho, CC, Falqueto A, Delmaestro, D, Barros GC. Mattos EA, et al. Distribuição geográfica da leishmaniose tegumentar americana no Estado do Espírito Santo, Brasil. Rev Soc Bras Med Trop. 1985;18:237-41.

26. Falqueto A, Sessa PA. Leishmaniose tegumentar americana. In: Veronesi R, Focaccia R, editores. Tratado de infectologia. São Paulo: Atheneu; 1996: p.1221-33.

27. Ministério da Saúde (Brasil). Fundação Nacional de Saúde. Manual de controle da leishmaniose tegumentar americana. $5^{\mathrm{a}}$ ed. Brasília. 2000. 64p.

28. Paes MG, Barros MLB, Ferreira LCL, Talhari S. Leishmaniose tegumentar americana. In: Tonelli E, Freire LMS, editores. Doenças infecciosas na infância e adolescência. $2^{\mathrm{a}}$ ed. Rio de Janeiro: Medsi; 2000. p.1251-70.

29. Altamirano-Enciso AJ, Marzochi MCA, Moreira JS, Schubach AO, Marzochi KBF. Sobre a origem e disper são das leishmanioses cutânea e mucosa com base em fontes históricas pré e pós-colombianas. Hist Cienc Saude-Manguinhos. 2003;10:853-82.

30. Moreira J. Botão endêmico dos países quentes. Brasil Med; 1906;1:100-1.

31. Pupo JA. Leishmaniose tegumentar. Epidemiologia, profilaxia e tratamento da leishmaniose americana. Ciência Med. 1926; 4:387-409.

32. Herrer A. Antiguedad de la leishmaniasis tegumentaria en América. Rev Bras Malariol. 1956;8:187-96.

33. Marzochi MCA, Marzochi KBF. Tegumentary and visceral leishmaniasis in Brazil-emerging anthropozoonosis and possibilities for their control. Cad Saude Publ. 1994;10:S359-75.

34. Pessoa SB, Barreto MP. Leishmaniose tegumentar americana. Rio de Janeiro: Ministério da Educação e Cultura; Serviço de Documentação. 1948. 527 p.

35. Oliveira-Neto M, Marzochi MCA, Grimaldi Jr. G, Coutinho S, Pirmez C. Study of an outbreak of American cutaneous leishmaniasis (ACL) by L. b. braziliensis in a periurban area of the city of Rio de Janeiro, Brazil. 17th World Congress of Dermatology; Short Communications; Part II; p. 20; 1987; Berlin, Germany.

36. Gomes RF, Macedo AM, Pena SD, Melo MN. Leishmania (Viannia) braziliensis: genetic relationships between strains isolated from different areas of Brazil as revealed by DNA fingerprinting and RAPD. Exp Parasitol. 1995;80:681-7.

37. Schubach A, Marzochi MC, Cuzzi-Maya T, Oliveira AV, Araujo ML, Oliveira AL, et al. Cutaneous scars in American tegumentary leishmaniasis patients: a site of Leishmania (Viannia) braziliensis persistence and viability eleven years after antimonial therapy and clinical cure. Am J Trop Med Hyg. 1998;58:824-7.

38. Coimbra Jr. CE, Santos RV, do Valle AC. Cutaneous leishmaniasis in Tupi-Mondé Amerindians from Brazilian Amazonia. Acta Trop. 1996;61:201-11.

39. Dujardin JC, Henriksson J, Victoir K, Brisse S, Gamboa D, Arevalo et al. Genomic rearrangements in trypanosomatids: an alternative to the "one gene" evolutionary hypotheses? Mem Inst Oswaldo Cruz. 2000;95:527-34.

40. Altamirano-Enciso AJ. Comprometiendo la estructura osteo-facial de las poblaciones humanas del antiguo Perú por la leishmaniasis tegumentaria de forma mucosa. [tese]. Rio de Janeiro: ENSP/Fiocruz; 2000. 213p.

41. Thomas-Soccol V, Lanotte G, Rioux JA, Pratlong F, Martini-Dumas A, Serres E. Monophyletic origin of the 
genus Leishmania Ross, 1903. Ann Parasitol Hum Comp. 1993;68:107-8.

42. Lainson R, Shaw JJ. New World Leishmaniasis - The neotropical Leishmania species. In: Cox FEG, Kreier JP, Wakelin D, editors. Microbiology and Microbial Infections. Parasitology. 9th ed. London/New York: Topley \& Wilson; 1998. p. 241-68.

43. Noyes $\mathrm{H}$. Implications of a neotropical origin of the genus Leishmania. Mem Inst Oswaldo Cruz. 1998;93:657-61.

44. Kern S. Paleartic origin of leishmania. Mem Inst Oswaldo Cruz. 2000; 95:75-80.

45. Momen H, Cupolillo E. Speculations on the origin and evolution of the genus Leishmania. Mem Inst Oswaldo Cruz. 2000; 95:583-8.

ENDEREÇO PARA CORRESPONDÊNCIA:

Everton Carlos Siviero do Vale

Rua Orenoco, 51/502

30310-060 - Belo Horizonte - MG

Tel.: (31) 3241-2535

E-mail: everton.vale@terra.com.br 